\title{
Dos lados opuestos y una experiencia fronteriza: deixis del cruce en los relatos de Rosario Sanmiguel y Sandra Cisneros*
}

\author{
Edith Mora Ordoñez ${ }^{1}$ \\ Universidad de Sevilla (España)
}

\section{Resumen}

Las literaturas de la frontera en México y chicana en Estados Unidos traducen diversas perspectivas $\mathrm{y}$ significaciones de identidad fronteriza desde ambos territorios. Este trabajo realiza una interpretación de los relatos "Bajo el puente" y "Las hilanderas", de Rosario Sanmiguel (1994) y La casa en Mango Street, de Sandra Cisneros (2009), con el objetivo de establecer relaciones dialógicas entre la construcción simbólica de los espacios vinculados con el lugar de origen -la casa- y los lugares situados en una instancia imaginaria al otro lado de la frontera. El análisis se aborda metodológicamente desde el enfoque de la "pragmática literaria" y se apoya en los recursos literarios de la "deixis", de acuerdo con la enunciación de posiciones y desplazamientos de los personajes, así como en las metáforas de cruce de la frontera.

Palabras clave: literatura, frontera, deixis, casa, imaginario

\section{Abstract}

The literatures of the border in Mexico and Chicana in the United States render diverse perspectives and meanings of border identity from both sides of the borderline. This work is an interpretation of the stories "Debajo del puente" and "Las hilanderas", by Rosario Sanmiguel (1994) and La casa en Mango Street, by Sandra Cisneros (2009), with the aim of establishing dialogical relations between the symbolic construction of spaces linked to the place of origin -the house- and places located in an imaginary instance on the other side of the border. The analysis is approached methodologically from the viewpoint of "literary pragmatics" and is based on the literary resources of the "deixis," according to the enunciation of positions and displacement of the characters, as well as the metaphor of crossing the border.

Keywords: literature, border, deixis, house, imaginary

\footnotetext{
* Two opposite sides and a border experience: deixis of the cross in the stories of Rosario Sanmiguel and Sandra Cisneros

1 Doctora en Literatura y Comunicación del Programa de Estudios Culturales, por la Universidad de Sevilla. Investigadora de la Universidad de Sevilla. Correo electrónico: emoraordonez@gmail.com
} 
Uno ve el paisaje al otro lado de la ventanilla y descubre, entonces, qué es exactamente el verbo extrañar, el sustantivo nostalgia, el subjuntivo si hubiera, el futuro condicional. Después, en el anonimato del otro lugar, uno prevarica. Uno inventa un origen y un pasado y, si se puede, lo que vendrá. Luego sólo queda el arrebato que provoca a veces esa corteza, aquella montaña, ese pedazo de ciudad, esta luz.

(Cristina Rivera Garza, Los muertos indóciles)

\section{Representaciones de la frontera desde ambos lados}

La experiencia del sujeto fronterizo inscribe localizaciones físicas imprecisas, desplazamientos constantes, pero, sobre todo, como plantean las literaturas de la frontera en México y chicana en Estados Unidos, implica múltiples posiciones imaginarias entre su ser aquí y ser allá. Las visiones desde ambos lados de la línea fronteriza mexicana-estadounidense responden a perspectivas diversas, de acuerdo con el lugar en el que se ubican los sujetos que la viven, practican y definen. En relación a estas premisas se plantea la interpretación de los relatos "Bajo el puente" y "Las Hilanderas", incluidos en Callejón Sucre y otros relatos (1994), de la escritora mexicana Rosario Sanmiguel, y la novela en relatos titulada La casa en Mango Street (2009), de la escritora chicana Sandra Cisneros. El objetivo general es identificar claves de significación colindantes en las narrativas fronterizas de ambos lados. Específicamente, se propone reconocer imaginarios de la frontera a partir de la enunciación deíctica de los personajes, en este caso femeninos, en particular, la construcción de figuraciones acerca de "la casa", "lugar de origen" y "el otro lado", cuando se trata de espacios desconocidos, imaginados y deseados. Se advierte, en el sentido argumentado por Bruce-Novoa, la desarticulación de la visión de esta frontera en tanto utopía, pues "para unos será la tierra prometida; para otros será el paraíso perdido, y para otros más se convertirá en un infierno" (citado en Tabuenca, 1997: 92).

Los relatos de ambas autoras establecen una relación dialógica mediante la representación de personajes que rechazan el lugar del presente y miran hacia afuera, donde se ubica la instancia de "lo otro", en un punto imaginario, más allá de la línea fronteriza, y que constituye un lugarideal o referente de "espacio sagrado" (Mircea Eliade, 1999). Las miradas en estos relatos, dirigidas al lado opuesto, una hacia México, otra hacia Estados Unidos, se cruzan en dicha búsqueda, mostrando una relación especular. Los significados del es- 
pacio de origen, idealizado, se difuminan a cambio de la experiencia de desplazamiento y la configuración de identidades subjetivas, "en proceso", o asimiladas como permanentemente fronterizas.

El análisis de dichos relatos se aborda mediante el enfoque de la pragmática literaria (Pozuelo Yvancos1994)2, debido a la implicación de los contextos culturales en la enunciación de los discursos. Principalmente, se aplican criterios de la "deixis" (Karl Bühler, 1985), en este caso deixis literaria. Esta aproximación toma en cuenta las referencias a la semiotización de los espacios de acuerdo con el lenguaje de los personajes, los cuales explicitan verbalmente sus posiciones y percepciones de lugar mediante indicativos como "aquí", "allá", "acá", "de este lado", "del otro lado", y establecen un código de significaciones respecto a las instancias "adentro" y "afuera". Otros referentes deícticos sobre el espacio de acción de los sujetos en los relatos estudiados se identifican a través de la representación de imágenes como la ventana y el puente. Ambas intervienen en forma de claves simbólicas de la frontera. La disposición de los espacios narrados mediante este lenguaje deíctico-simbólico traduce la permeabilidad de códigos culturales entre la literatura chicana y la mexicana de la frontera.

\section{Literaturas fronteriza y chicana: Rosario Sanmiguel y Sandra Cisneros}

Las literaturas de la frontera norte de México, o fronteriza, y chicana, igual que la crítica fronteriza en México y borderlands en Estados Unidos, han mostrado desarrollos distintos, manteniendo su independencia una de la otra y en relación a las literaturas nacionales. Manuel de Jesús Hernández-G (2012) advierte una tendencia unilateral entre los críticos mexicanos y chicanos al abordar dichas literaturas (32). Cárdenas propone pasar "de la crítica borderlands a la crítica biborderlands" (cit. en Hernández G., 2012: 56), puesto que, como señala Hernández, "raro es el crítico literario que relaciona e interrrelaciona de manera extensa y profunda las dos producciones fronterizas" (55).

La literatura de ambos lados, así como los discursos teóricos y críticos sobre las mismas, ha revisado la problemática a partir de la compleja formación de dicha zona limítrofe: por una parte, desde su

\footnotetext{
2 La teoría semiótica que aborda específicamente el proceso comunicativo del texto literario, advirtiendo su implicación social, es la Pragmática. De la Pragmática Lingüística se desprende la Pragmática Literaria que "estudia las relaciones que mantienen el emisor, el receptor, el signo y el contexto de comunicación..." (Pozuelo Yvancos, 1994, p. 75).
} 
desarrollo histórico, geográfico, económico, político y, por otra, en relación a la dinámica de cruces culturales y simbólicos. Las conclusiones de numerosos textos al respecto coinciden en la configuración de una frontera movediza, dinámica, porosa, determinada mayormente por la productividad de significaciones simbólicas.

Una primera percepción simbólica de la frontera remite a la división trazada en el contexto histórico de Los Tratados de Guadalupe Hidalgo en 1848, por la cual, señala José Manuel Valenzuela Arce (2003), se identifican metáforas "como la ruptura, la pérdida, la traición, el puente, el muro de contención, los intersticios, la transnacionalización" (33). A partir de esta fractura geográfica o física, deviene esa otra escisión que implica a los espacios subjetivos, mediante los cuales se configuran las nuevas identidades colindantes: una en el norte de México, asumida por quienes Roxana Rodríguez Ortiz llama "sujetos transfronterizos" (2013), y otra en el sudoeste de Estados Unidos, conformada por "sujetos chicanos", según la misma autora (16).

En el caso del surgimiento de la literatura fronteriza en México, Tabuenca habla de un boom de literaturas regionales alrededor de la década de 1980, como resultado de un proceso de descentralización en el mismo país, mientras que la literatura chicana se desprende de los movimientos de resistencia impulsados por las mujeres, durante la década de los sesenta, desde los cuales reclamaban sus derechos civiles. Sin embargo, el auge de esta última se une al de la literatura mexicana durante los años ochenta, como un discurso "contestatario", que, en el contexto estadounidense, menciona Norma Klahn (2003), tenía el fin de desestabilizar los paradigmas modernos del Estado-nación, asimilacionistas y homogeneizantes y, en efecto, exclusivistas (113). Klahn señala que el levantamiento zapatista de 1994 en México y las reivindicaciones indígenas consecuentes promovieron diálogos entre mujeres chicanas y mujeres indígenas mexicanas. En dicho entorno de conflicto se generó la inquietud de las escritoras y sus "discursos feministas contrahegemónicos que entienden identidades y culturas como transformativas, en constante re (definición) y (re)contextualización" (126).

Borderlands/ La Frontera: The New Mestiza, de Gloria Anzaldúa, en 1987, sería el primer texto reivindicativo en ese sentido y el primero en delinear las fronteras simbólicas y sus cruces. Desde entonces, la representación del espacio ideológico predomina en la literatura chicana, mientras que, según refiere Rodríguez Ortiz (2013), el escenario urbano es motivo central de la literatura fronteriza (16).

En el corpus de la literatura fronteriza en México, los relatos de Rosario Sanmiguel son precursores en el abordaje narrativo de los 
tópicos que abordan las problemáticas de la frontera con Estados Unidos y del inicio de una escritura femenina que actualmente ha extendido sus voces. Callejón Sucre y otros relatos, publicado en 1994, está conformado por siete relatos cuyos personajes protagonistas son mujeres que transitan en el escenario de la fronteriza Ciudad Juárez. El estudio que hace Rodríguez Ortiz (2013) sobre cinco relatos de este libro distingue tres tipos de espacios: el extrínseco, ligado al entorno urbano; el intrínseco, relacionado con la conciencia de los personajes y el semántico o metafórico (244). La académica menciona la deixis espacial como pauta de análisis de los relatos de Sanmiguel, y presenta "la yuxtaposición de lo interno y de lo externo, del adentro y afuera, de manera objetiva y subjetiva", como evidencia de la contigüidad espacial, fundamental en la escritura fronteriza (275). En otro texto crítico Jesús Barquet señala la pertinencia de realizar lecturas feministas sobre dichos relatos, pero enfatiza que sobre todo obligan a identificar la presencia de "una metaforización de la conformación de una intimidad migrante", "la frontera como una abstracción que delimita otredades", y "la transgresión como estrategia del individuo" para entenderse (Barquet, 2008: 86-87).

Por otra parte, La casa en Mango Street, novela de Sandra Cisneros publicada originalmente en inglés como The House on Mango Street en $1984^{3}$, y editada por primera vez en español en 1995, es una de las obras de la literatura chicana más leídas por la crítica y, particularmente, por las instancias académicas del sudoeste estadounidense. Los estudios realizados se centran en la recreación de los lugares habitados por los personajes, especialmente la casa, o lo "sagrado del hogar, como el lugar de introspección e inspiración: un sitio acogedor que le recuerde sus orígenes" (Rodríguez Ortiz, 2013: 162); espacios que tienen la función de "representar la dimensión ideológica" e intervienen así mismo en "la construcción identitaria del sujeto chicano" (162). Por otra parte, la lectura de Norma Klahn (2006) enfatiza la representación de la "conciencia de marginalidad" del personaje principal. Considera que "no existe nostalgia en su relato, no hay ilusiones pasadas, no hay celebración de la comunidad. El acto de recordar se vuelve reminiscencia y nombramiento doloroso de la marginalidad, la desigualdad, la injusticia y la pobreza sufridas en el barrio" (189). De esta condición se deprende un impulso de búsqueda y emancipación.

3 Para este trabajo se lee La casa en Mango Street, traducida al español por Elena Poniatowska y Juan Antonio Ascencio, en la segunda edición (2009) de Vintage Español, Random House, Inc. 


\title{
La construcción deíctica de la frontera
}

Los relatos de Sanmiguel y Cisneros sugieren una interpretación discursiva a partir de la deixis espacial. Los personajes principales, situados en un punto fronterizo, fragmentado en múltiples líneas de transición, se expresan mediante un lenguaje de posiciones y referencias. Según explica Karl Bühler (1985), en el plano de coordenadas donde se sitúan los sujetos hay un lugar fijo determinado como "cero", el cual corresponde a la situación aquí-ahora-yo. A partir de este eje, "cada uno se comporta bien orientado en su conducta y entiende la del prójimo" (121). En ese sentido, la enunciación de espacios a través de demostrativos y adverbios de lugar se entiende dentro de un universo semiótico-pragmático, donde los recursos lingüísticos "aquí", “allá", "acá", "de este lado", "del otro", "afuera”, "adentro", denotan, además de la ubicación física de los personajes, una situación o contexto, un mapa de relaciones subjetivas y simbólicas:

\begin{abstract}
Tratándose de deixis literaria, es justamente su nivel simbólico el que debe ser abordado de manera inexcusable, pues en él descansan las significaciones, él sostiene el funcionar artístico que lo literario implica el lenguaje verbal. En literatura, la deixis es conductora de tanto simbolismo como cualquier otro signo (Barroso Villar 2004: 55).
\end{abstract}

Por lo tanto, a este léxico de coordenadas se adhiere también la verbalización de elementos espaciales deícticos que cumplen, ya de por sí, una función simbólica, como la ventana, el puente y la casa.

\section{La casa al otro lado}

La casa en Mango Street narra la infancia de Esperanza, una niña nacida en Estados Unidos, de padres mexicanos inmigrantes. Los relatos, escritos en primera persona, describen la vida cotidiana del personaje en el perímetro de un barrio chicano, dentro de una casa que no desea habitar, pues no la asocia con la vivienda de sus orígenes mexicanos, según las historias familiares, las fotografías y la propia imaginación. La casa debería ser un referente en la reconstrucción de la memoria y la identidad, sin embargo, sus recuerdos a partir de ésta se encuentran fragmentados. Son un conjunto de piezas dispersas. Durante su infancia Esperanza ha hecho varias mudanzas con su familia, de manera que le resulta difícil ligar el espacio de origen y los afectos a un lugar específico. Se enfrenta a la imposibilidad de construir una idea de "espacio sagrado", en el sentido filosófico plan- 
teado por Mircea Eliade (1999): un lugar fijo donde el hombre crea y funda el mundo, el "Universo privado" desde el cual se orienta en la "homogeneidad caótica" (121-123). Esperanza añoraba el día en que se mudaran a "una casa de verdad, que fuera nuestra para siempre, de la que no tuviéramos que salir cada año, [...] es la que mamá soñaba en los cuentos que nos contaba antes de dormir" (Cisneros, 2009: 4). La primera, la casa natal, escribió Gastón Bachelard (2012), más que un cuerpo de vivienda, es un cuerpo de sueño (46), de "imágenes que dan al hombre razones o ilusiones de estabilidad" (48). Esperanza es consciente de este desarraigo y entiende la necesidad de buscarse una casa propia en la que pueda poner los cimientos de una persona que ya dibuja cómo ha de ser.

La casa en Mango Street es la primera vivienda que pertenece a la familia, por lo tanto, podría ser apreciada como el lugar fijo, o lugar de partida, pero Esperanza no se apropia de ella, se desconoce en su interior: "No, ésta no es mi casa, digo yo y sacudo mi cabeza como si con sacudirla pudiera borrar el año que he vivido allí. Yo no soy de aquí. No quiero nunca querer ser de aquí" (Cisneros, 2009: 108). El personaje manifiesta su distancia afectiva con el espacio. Se niega a habitarlo como ha hecho en las ocasiones anteriores. El movimiento que hace con la cabeza constituye un componente deíctico por el que, en vez de señalar, difumina la casa real; ésta, a pesar de estar materialmente localizada, no hace parte de su mundo. La experiencia se repite cuando Esperanza observa la casa desde afuera, con extrañamiento. Una monja a la que encuentra en la calle, le pregunta dónde vive y ella responde:
Allí. Tuve que mirar a donde ella señalaba [...] ¿Vives allí? El modito en que lo dijo me hizo sentir una nada. Allí. Yo vivo allí. Moví la cabeza asintiendo. Desde ese momento supe que debía tener una casa. Una que pu- diera señalar (Cisneros, 2009:5).

La omisión de la señal indicativa que normalmente se hace con el dedo, a cambio del impreciso gesto de negación con la cabeza, expresa la sensación de vaguedad, presente en el personaje a lo largo del texto, desde la cual se configura no solo su condición errante, sino la identidad múltiple, en constante desplazamiento. Si el hombre careciera de casa, dice Bachelard (2012), "sería un ser disperso" (37), pero en el caso del relato del personaje, cuya situación migrante es adquirida desde el nacimiento, la indefinición del hogar se plantea como una condición fronteriza y constituye otra forma de habitar el mundo. Lo dice Cristina Rivera Garza, cuando expresa que todo 
lugar no es una entidad fija, sino una relación imaginaria. En principio, escribe, cuando se impone un punto de vista conservador, el origen se une obligadamente al sujeto para reconocer su identidad, pero, en realidad, esta regla puede romperse para adoptar diversos referentes:

\begin{abstract}
Un sujeto, se dice, debe ser de un lugar; de preferencia, aunque no siempre, el de nacimiento [...] Uno pasa por muchos lugares después de todo y uno se enraíza, si verdaderamente pasa [...] Para el que parte, el lugar lo es todo. Para el que parte, el lugar no es nada (Rivera Garza, 2013: 136).
\end{abstract}

Desde esta perspectiva, el lugar de "origen" podría ser un cúmulo de lugares, o podría prescindirse de éste como referente, liberando a los personajes, a los sujetos fronterizos, de la tensión de la pertenencia, de la condición de la casa para responder a la norma y conformar desde allí una identidad específica que pueda ser igualmente pronunciada.

En el relato "Las hilanderas", de Rosario Sanmiguel, una mexicana llamada Fátima narra su infancia al lado de su madre cuando trabajaban como empleadas domésticas en una casa en El Paso, Texas, cerca de la frontera. La madre, que decidió dejarla en esta ciudad para volver a México, le escribe para insistirle en que permanezca en la casa de Texas y para recordarle que "del otro lado" no posee nada. "¿Y en El Paso?", se pregunta Fátima: "un pobre salario, un cuarto de baño y una televisión prestada. Nada me pertenecía" (1994: 72). Antes de marcharse, Fátima recuerda que su madre "hablaba para sí misma mientras [yo] crecía solitaria en aquellos corredores ajenos, entre los muebles que las dos bruñíamos a diario con aceites aromados" (70). La asimilación de un espacio como propio está ausente también en este personaje que se refiere al lugar que habita nombrando un entorno ajeno. Cuando pronuncia "en El Paso" no se proyecta materialmente en un espacio "aquí", de manera que siempre hay una posición deíctica de distancia, hasta ahora indeterminada, respecto a la figura de la casa. En ese sentido, se revierte la asociación simbólica de la casa como recinto de recuerdos, resguardo de los sueños o nido. Sería, por el contrario, un lugar de aprisionamiento en cuyas formas y límites se recrea la doble opresión de los personajes femeninos, frente al patriarcado, y fronterizos frente a la indefinición de su identidad, así como su marginalidad. Los espacios descritos por ambas autoras coinciden en su pequeñez y sofocamiento. Esperanza detalla que "la casa es pequeña y roja y con escalones apretados al 
frente y unas ventanitas tan chicas que parecen guardar su respiración" (Cisneros, 2009, 3), mientras que Fátima vive sus días entre el trabajo doméstico y el tejido, "lentamente, como si cruzara un pantano" (Sanmiguel, 1994, 71). Cuando siendo joven sale un día a divertirse del otro lado de la línea fronteriza, en Ciudad Juárez, y, en su regreso a El Paso es detenida junto con otras mujeres por la policía de migración, la celda donde son encerradas no le provoca ninguna angustia. El encierro experimentado por este personaje en la cárcel es un estado que le resulta familiar. Tiene la habilidad de contrarrestarlo con el hábil manejo del tiempo y el respeto de los ritmos cotidianos. Ha desarrollado sus propios modos de resistencia. Su madre le había enseñado a tejer "el transcurso de las horas en las habitaciones silentes de la casona" (71) y aprendió a ponerlo en práctica fuera de ésta. Después de esa noche Fátima decide quedarse en México y emprender la búsqueda de la casa propia, siguiendo los pasos que su intuición le sugiere a partir de las historias e imágenes narradas por su familia mexicana. Sin embargo, como se menciona antes, la casa es una construcción imaginaria, una ensoñación acerca del lugar perdido en el otro lado de la frontera. Finalmente, el personaje decide quedarse porque es una forma de ir, o volver, al lugar de donde alguna vez partió, siguiendo los pasos de su madre, aunque todavía no hubiera nacido. El origen se asocia al territorio materno. En ese sentido ocurre, como señala Fernando Aínsa (2012), que "se puede regresar a un país donde no se ha nacido, pero al cual sientes que perteneces" (160). La casa es, nuevamente, no el lugar de origen, sino el punto de llegada.

El anhelo de Esperanza, en el texto de Cisneros (2009), surge de las imágenes transmitidas oralmente por sus padres acerca de su país de origen. Narra que "un día íbamos pasando una casa que se parecía, en mi mente, a las casas que he visto en México, no sé por qué" (17). "Miren esa casa, dije, parece México" (18). La niña, que anteriormente frente a la monja señaló con titubeo su casa en Mango Street, indica ahora, con firmeza y aprobación, la casa que asocia con México, un punto situado, como en los sueños, en otra parte a la que sí desea pertenecer. José Manuel Valenzuela Arce (2003) plantea que "existen también posiciones que no toman en cuenta la relación superior/inferior, como la de Graham Greene, para quien la frontera es un espacio imaginado o un más allá que alienta el deseo y la posibilidad de empezar algo nuevo" (42). El umbral ${ }^{4}$, sobre el que se sitúan los personajes es, por un lado, una escisión que impide la formación

4 La frontera puede ser considerada el "umbral" haciendo referencia al concepto de cronotopo aportado por Bajtin. El cronotopo del umbral representa un punto medio en el que ocurre "la crisis y la ruptura [...] de la decisión que modifica la vida (a la falta de decisión, al miedo a atravesar el umbral)" (Bajtín, 1989: 399). 
de afectos y la estabilidad de la identidad, pero, por otro, puede ser vivido como una oportunidad o una experiencia creativamente productiva. Bachelard (2012) también señala que "a veces, la casa del porvenir es más sólida, más clara, más vasta que todas las casas del pasado. Frente a la casa natal trabaja la imagen de la casa soñada. Ya tarde en la vida, con un valor invencible, se dice: lo que no se ha hecho se hará. Se construirá la casa" (93).

"Allá", donde se ubica la casa soñada, representa un destino variable en estos relatos, pues invierte su significación según las circunstancias o situaciones en ambos textos y ambos lados: México es ese "allá" para el personaje que narra desde Estados Unidos, y este último país es "allá" desde la perspectiva del sujeto que habita en México. Cada uno es "allá" y es "aquí", según el contexto. En un lado se localiza el "sueño americano", mientras que, en otro, el lugar donde residen los habitantes de la misma comunidad de Aztlán ${ }^{5}$.

Esperanza experimenta un cruce de fronteras simbólicas dentro del mismo entorno familiar y social chicano y, así mismo, a través de su contacto con el espacio y la cultura estadounidense. En cambio, Fátima, en el relato de Sanmiguel, transita entre uno y otro lado de la frontera geográfica o física, atravesando el puente entre las dos ciudades colindantes: Ciudad Juárez y El Paso. Las dos mujeres penetran, de formas diversas, en el espacio material y simbólico del otro. La vida fronteriza, según Valenzuela Arce (2003), "implica redes y relaciones familiares o amistosas ancladas en ambos lados [...] obliga, entonces, a incorporar 'el otro lado', puesto que éste la constituye" (171). Para explicar la identidad de los sujetos en la frontera es necesario pensar en términos de alteridad, pues, como señala De Michiel, "ambas lenguas", que aquí podríamos considerar dos códigos culturales, "son necesarias en el funcionamiento de una cultura bifronteriza, porque de ese modo manifiestan 'la necesidad del otro; de otra persona, de otra lengua, de otra cultura" (citado en Silva Rodríguez, 2012: 15). Esta figura del otro no llega nunca a concretarse, sino que permanece en la imaginación de los personajes como una forma de deixis en phantasma. En ésta, el demostrativo "allá", enunciado por los personajes desde sus posiciones opuestas y especulares, refiere a una situación que ocurre, citando a Bühler (1985), "cuando un hombre despierto y que está en sí (por tanto no un soñador) hablando y describiendo

5 Explicado por Gloria Anzaldúa (2016), Aztlán es el lugar donde habitaron los primeros aztecas, situado en el suroeste de Estados Unidos, en el año 1168. Posteriormente emigraron hacia el sur para instalarse en lo que hoy es México. Algunos descendientes se llaman a sí mismos Chicanos y consideran que este territorio, Aztlán, es su patria (39-43). 
él mismo o como oyente (lector) se hunde en recuerdos o emprende viajes fantásticos y realiza construcciones fantásticas" (151).

"Bajo el puente", relato de Rosario Sanmiguel, narra en primera persona la historia de Mónica, una mexicana empleada de un restaurante, y su relación con Martín, un joven que se dedica a cruzar migrantes a Estados Unidos a través del Río Bravo. Mónica le pide ayuda para pasar al otro lado, pues desea adentrarse en el paisaje que contempla en trozos desde Ciudad Juárez: "a pesar del miedo que llevaba me ilusionó pensar que allá nos quedaríamos el resto del día, que íbamos a caminar por las calles de una ciudad desconocida para mí, eso me entusiasmó, miré el cielo azul, la Montaña Franklin, los edificios de colores, un cartel enorme de los cigarros Camel" (1994: 48). Mónica ve más cerca la oportunidad de cruce y refuerza su tentación hasta convertirla en necesidad, porque ha encontrado en Martín a un barquero como Caronte. La posibilidad de llegar a "allá", al otro mundo a través del pasaje prohibido, alimenta sus ensoñaciones.

\section{Ventana y formas imaginarias del cruce}

La ventana constituye un punto "cero" (Bühler, 1985:121), o punto de referencia a partir del cual se organiza el espacio descrito por los personajes situados al pie de ésta. Igual que la puerta, cumple una función de paso o trance, pero no estrictamente implica el tránsito. La acción de mirar por la ventana, que ejerce de referente deíctico, incorporando un elemento simbólico, supone una separación de los sujetos con el espacio exterior, lo que está del otro lado y que, en el caso de los relatos, representa un entorno lejano y deseado. La descripción de la ventana retiene dos significaciones en la obra de Cisneros: una denota la espera, otra simboliza el anhelo. Esperanza es consciente de que en su propio nombre lleva la espera. Es el mismo que tenía su abuela, cuya historia no desea repetir: "Heredé su nombre, pero no quiero heredar su lugar junto a la ventana" (Cisneros, 2009: 11). La asociación de la ventana con el obstáculo es recurrente; los personajes permanecen inmóviles frente a ella, se mantienen a la expectativa, luchando contra la imposibilidad de cruzar. La imagen incide en el discurso de la misma niña cuando vuelve a renegar de su casa en Mango Street: "Quiero ser toda nueva y brillante [...] No cada noche hablarles de este modo a los árboles, asomarme por la ventana, imaginar lo que no alcanzo a ver" (74). Desde el coche, con la familia, siente vergüenza de "todos nosotros mirando por la ventana como los hambrientos", y dice: "estoy harta de ver lo que no puedo tener" (88). La imagen de la ventana establece una frontera entre la realidad y el sueño, la pobreza y la riqueza, la casa sin recuerdos y la casa que aguarda el pasado. Esperanza busca la opción 
del lugar seguro en el México de su imaginación, de donde han venido sus padres trayendo consigo un equipaje de signos que ella utiliza para reconstruir el universo desde las ventanas. Lo mismo, aunque sin resistencia, ha hecho el escritor Andrés Neuman, quien desde España miraba a la Argentina de su infancia:

\begin{abstract}
Nacer en un edén para alejarse poco a poco se me antoja, como mínimo, una falta de cortesía con el presente. Mi niñez nunca fue un paraíso. Eso seguro. Pero estoy convencido de que todas las infancias tienen su lugar sagrado, un pequeño reducto donde escapar de algún infierno (citado en Aínsa, 2012: 149).
\end{abstract}

Tanto en Neuman, como en Esperanza, hay una conciencia de huida. Ella no solo se percata de esta experiencia vinculada a las ventanas de su casa, sino que observa otras en el mismo barrio, por ejemplo, la de una mujer llamada Rafaela, quien llega desde México un día para vivir en la casa de su hijo en Estados Unidos. Esperanza contempla y escucha su lamento desde el exterior:

Todo el día se sienta junto a la ventana y sintoniza el radio en un programa en español y canta todas las canciones nostálgicas de su tierra con voz que suena a gaviota. Hogar. Hogar. Hogar es una casa en una fotografía, una casa color de rosa, rosa como geranio con un chorro de luz azorada (Cisneros, 2009:79).

El radio funciona para Rafaela como fórmula de escape, mientras que recrea la casa, ya desdibujándose en su memoria, a través de los recursos de los que dispone en el nuevo espacio donde habita junto a su hijo. La ventana vuelve a mostrarse como una metáfora de la separación con el espacio anhelado, aunque, en el caso de Rafaela, el referente anafórico al cual interpela, no la conecta con un lugar imaginado, producto de un sueño, como le ocurre a Esperanza, pues, más bien, la desprende violentamente del hogar que habitó la mayor parte de su vida. En este sentido, la ventana, trasunto de la frontera, la aísla del mundo tangible, representado por la mexicanidad que evoca desde el recuerdo. Esperanza, en cambio, refiere a una fantasía. Le dice a su amiga, quien vino de Guadalajara con sus padres: "Tú tienes casa, Alicia, y algún día irás para allá, a una ciudad que recuerdas, pero yo, yo nunca he tenido una casa, ni siquiera en fotografía... sólo una con la que sueño" (109). 
Desde el lado mexicano, los personajes de "Bajo el puente" señalan con añoranza el mundo del otro lado de la frontera, el cual representa la oportunidad de alcanzar una vida económica y socialmente mejor. Mónica y Martín se hospedan en la habitación de un hotel para pasar una noche en la que puedan desconectar del entorno real al cual no desean pertenecer. El hotel representa el lugar de paso, de libertad y anonimato. El tiempo y lo que ocurre entre las paredes de la habitación forma parte de un reducido universo postizo. En ella los personajes miran a través de la ventana imágenes que recrean para sumergirse en ensoñaciones:

Martín pidió un cuarto en el tercer piso, que era el último, con ventana a la Degollado, desde allí oíamos el ajetreo de la ciudad como un rumor lejano, contra la esquina del hotel hay un anuncio luminoso que echa una luz rosada, y a Martín le gustaba que entrara ese resplandor al cuarto, decía que se sentía en otro lugar, que hasta él mismo se sentía como una persona diferente" (Sanmiguel, 1994: 45).

La lectura simbólica de la ventana, sobre todo al situarse en lo alto de una torre, remite a la conciencia (Cirlot, 2006: 462). Los personajes realizan un ejercicio introspectivo desde dicho lugar de distanciamiento en el que disponen de una perspectiva distinta a la habitual. Por otra parte, el desplazamiento de los personajes en este relato dibuja continuamente trayectos en círculo, de idas y vueltas entre los dos países y a través de Ciudad Juárez. El discurso de la narradora es reflexivo y traduce la situación de estancamiento experimentada por los sujetos fronterizos condenados a vivir precariamente del lado mexicano. Mónica cruza finalmente hacia Estados Unidos, pero no se queda, y Martín muere en el camino de vuelta a México. La mirada hacia el otro lado, que parece inalcanzable en este relato, rompe con la idea de un imaginario de sueños perseguidos en torno al mito americano del progreso; lo que señala es la diferencia de espacios urbanos, las distancias sociales y culturales que enfatizan la propia condición periférica de los personajes atrapados en "este lado": "me acomodé bajo el puente y para distraerme me puse a mirar las nubes y los edificios de la ciudad que tenía enfrente, eran muy altos, torres de cristal de distintos colores, verde, azul, plomo, negro" (Sanmiguel, 1994: 44). El puente funciona de manera similar a la ventana en esta expresión, dado que "media entre dos mundos separados, el traspaso de un estado a otro, el cambio o el anhelo de cambio" (Cirlot, 2006: 379). El traspaso, el constante desplazamiento entre un lugar y otro, actúa como estrategia de regeneración del deseo y de la bús- 
queda, si se entiende, desde el pensamiento de Bachelard (2012), que "más vale vivir en lo provisional que en lo definitivo" (94). Soñar la casa, en vez de poseerla, garantiza así el movimiento creativo y la oportunidad de establecer otra forma de vida.

\section{Conclusiones}

La configuración de los discursos en los textos de las literaturas chicana en Estados Unidos y fronteriza en México, varía de acuerdo con los códigos culturales y las experiencias de los personajes en cada lado de la frontera. Sin embargo, a partir de la interpretación de enunciaciones deícticas y claves de significación en los relatos de Cisneros y Sanmiguel, se comprueba la representación de prácticas comunes y universos simbólicos paralelos. Los personajes femeninos de ambos lados de la frontera comparten escenarios donde se manifiesta la ausencia de vínculos con la casa representada como lugar de origen y, así mismo, coinciden en la búsqueda de un espacio imaginado y deseado, localizado en otro lado de la frontera. Los espacios de idealización asociados a la casa invierten su significado de una literatura a otra y se miran de manera especular. Es decir, la casa contradice su simbolismo, arquetipo de seguridad, estado del alma o nido, pues representa un lugar de opresión para los personajes, tanto chicanos como mexicanos fronterizos. Paradójicamente, estos sujetos miran hacia el otro lado, un "allá" lejano y figurado, donde suponen o recuerdan la existencia del hogar: las raíces de Aztlán para la narradora desde el punto de vista chicano, o bien, la ciudad moderna donde se asienta el sueño americano, desde la perspectiva de la narradora mexicana.

La enunciación del espacio de los personajes, situados en un punto cero, o de cruce, en las dos literaturas, plantea una misma tensión relacionada con mundos fragmentados e identidades indefinidas, que deriva en un deseo de "volver" hacia el otro lado, imaginario, para construir la casa soñada. Las miradas se intersectan en algún lugar de este plano simbólico para establecer, a partir de allí, esa visión bifronteriza atenta al universo del otro, implicando, como propone Walter Mignolo (2003), la clave del pensamiento fronterizo, que consiste en "pensar desde conceptos dicotómicos en vez de ordenar el mundo en dicotomías" (150).

En efecto, los personajes no llegan a establecerse y a definirse en un punto específico, sino que se quedan en el camino o fracasan en sus intentos de cruce. No encuentran el otro lugar y la casa anhelada para fundar la identidad se desvanece, pero la imaginación de un destino les permite iniciarse en el trayecto y éste es, finalmente, su 
sentido práctico: el acto de resistencia que viene a partir de la voluntad de desplazamiento, una oportunidad creativa para articular identidades múltiples.Dicho estado, el de "sujeto en proceso" (Braidotti, 2004) ${ }^{6}$, en constante búsqueda y movimiento, sugiere lecturas e interpretaciones acerca de la configuración de nuevas subjetividades nómades, características de la posmodernidad, particularmente en los espacios fronterizos.

El análisis desde la perspectiva de los referentes deícticos ha sido, pues, significativo para identificar guiños simbólicos de una realidad vigente sobre el imaginario desde y sobre la frontera. Los textos de Cisneros y Sanmiguel entrañan, entre otras, esta mirada bifronteriza, necesaria y útil para comprender las complejas dinámicas de cruce y la permanente situación de incertidumbre o tránsito que experimenta la extensa población de los sujetos contemporáneos en torno a las fronteras.

\section{Bibliografía}

Aínsa, F. (2012). Palabras nómadas. Nueva cartografía de la pertenencia. (1a. ed). Madrid: Iberoamericana Editorial Vervuert.

Anzaldúa, G. (2016). Borderlands. La Frontera. La nueva mestiza. Madrid: Capitan Swing.

Bachelard, G. (2012). La poética del espacio. (2ª ed). Ciudad de México: Fondo de Cultura Económica.

Bajtin, M. (1989) Teoría y estética de la novela. Madrid: Taurus.

Barquet, J. (2008). La frontera en Callejón Sucre y otros relatos de Rosario Sanmiguel. En Nora Guzmán. (Ed.), Narrativa mexicana del norte. Aproximaciones críticas. (pp. 85-93) Monterrey: Ediciones Eon.

Barroso Villar, M. E. (2007): Sobre deixis e ideología en cuatro relatos breves de Francisco Ayala: más allá de idealismos. En M. A. Vázquez Medel y A. Sánchez Trigueros. (Eds), Francisco Ayala y América (pp. 53-72). Sevilla: Alfar ediciones.

\footnotetext{
6 La interpretación del desplazamiento de los personajes en los textos puede avanzar a través de la vertiente de los estudios feministas, retomando las teorías de Rosi Braidotti (2004) sobre "subjetividad nómade". Al respecto, señala: "La idea de sujeto como proceso significa que ya no es posible suponer que él/ella coincide con su propia conciencia, sino que ha de pensarse como una identidad compleja y múltiple (40). Luego, manifiesta: "El estilo nómade alude a las transiciones y a los pasos sin destinos predeterminados ni patrias perdidas. [...] La falta de hogar y el desarraigo constituyen poderosos significantes de nuestra situación actual" (216-217).
} 
Braidotti, R. (2004). Feminismo, diferencia sexual y subjetividad nómade. Barcelona: Gedisa editorial.

Bühler, K. (1985). Teoría del lenguaje. Madrid: Alianza Universidad.

Cirlot, J. E. (2006). Diccionario de símbolos.Madrid: Siruela.

Cisneros, S. (2009). La casa en Mango Street. (2ª ed). Nueva York: Vintage Español.

Eliade, M. (1999). Lo sagrado y lo profano. Barcelona: Paidós Orientalia.

Hernández, M de J (2012). De la crítica borderlands a la crítica biborderlands: Un nuevo discurso crítico descentrado y antihegemónico para los estudios literarios y culturales de la frontera México-Estados Unidos. En G. Silva Rodríguez y M. Hernández-G, (Eds.), Chican@s y mexican@s norteñ@s. Bi-borderlands dialogues on literary and cultural production. (pp.30-63). Ciudad de México: Ediciones Eón/Arizona State University.

Klahn, N (2003). Travesías /Travesuras des/vinculando imaginarios culturales. En J. M. Valenzuela Arce (Ed.), Renacerá la palabra. Identidades y diálogo intercultural. (pp. 111-130). Tijuana: El Colegio de la Frontera Norte.

(2006) (Re) mapeos literarios. Desplazamientos literarios de escritoras chicanas. En M. Belausteguigoitia y M. Leñero (Eds), Fronteras y cruces: cartografía de escenarios culturales latinoamericanos. (pp. 177-214). Ciudad de México: Universidad Autónoma de México.

Mignolo, W (2011). Historias locales/Diseños globales. Colonialidad, conocimientos subalternos y pensamiento fronterizo. Sevilla: Ediciones Akal.

Pozuelo Yvancos, J M. (1994). Teoría del lenguaje literario. Madrid: Cátedra.

Rivera Garza, C. (2013). Los muertos indóciles. Necroescrituras y desapropiación. Ciudad de México: Tusquets editores.

Rodríguez Ortiz, R (2013). Alegoría de la frontera México-Estados Unidos. Análisis comparativo de dos escrituras colindantes. Ciudad de México: Ediciones Eón.

Sanmiguel, R. (1994). Callejón Sucre y otros relatos. Tijuana: El Colegio de la Frontera Norte.

Silva Rodríguez, G. (2012). Reencuentro bifronterizo en el Paso del Norte: Historización de la literatura chicana y la mexica- 
na nordfronteriza. En G. Silva Rodríguez y M. Hernández-G. (Eds), Chican@s y mexican@s norteñ@s.Bi-borderlands dialogues on literary and cultural production. (pp. 13-25). Ciudad de México: Ediciones Eón/Arizona State University.

Tabuenca Córdoba, M S (1997). Aproximaciones críticas sobre las literaturas de las fronteras en Frontera Norte. Frontera Norte, Vol. 9 (18), 85-110. Recuperado de: https://fronteranorte. colef.mx/index.php/fronteranorte/article/view/1445

Valenzuela Arce, J M (2003). Centralidad de las fronteras. Procesos socioculturales en la frontera México-Estados Unidos. En J. M Valenzuela Arce (Ed.), Por las fronteras del norte. Una aproximación cultural a la frontera México-Estados Unidos. (pp. 3367). Ciudad de México: Fondo de Cultura Económica. 